\title{
EVALUATION OF THE DENTO-SKELETAL EFFECTS OF MINI-IMPLANT ASSISTED RAPID PALATAL EXPANSION IN A SAMPLE OF ADULT ORTH- ODONTIC PATIENTS: A PROSPECTIVE CLINICAL STUDY
}

\author{
AbdUllah Mohamed Bahaa*, Mohamed Helmy Saleh", Ramadan Yusuf Abu-Shahba***
}

\begin{abstract}
Objective: to evaluate the dentoskeletal effects of maxillary skeletal expander (MSE) in adult orthodontic patients, using Cone Beam Computed Tomography (CBCT). Patients and Methods: The current study was conducted on 14 adult orthodontic patients (4 males and 10 females), with their age ranged from 18 to 21 years, treated with a special type mini-implant assisted rapid palatal expander called, MSE (Maxillary Skeletal Expander) to correct transverse maxillary deficiency. The CBCT images were performed before the start of the orthodontic expansion (T1) and 3 months after the last activation (T2). Paired t-test, and descriptive statistics were used to evaluate the amount and the pattern of the mid-palatal suture opening, the total amount of maxillary expansion and the change in the inter-molar distance and molar inclination. Results: Four patients were dropped-out for different reasons, so, the statistical analysis was performed only on 10 patients ( 3 males, 7 females). The midpalatal suture split by $2.96 \mathrm{~mm}$ and $2.64 \mathrm{~mm}$ at the anterior nasal spine (ANS) and the posterior nasal spine (PNS) respectively, with a ratio of $89 \%$ between the PNS and the ANS. The maxillary width showed increase by $2.99 \mathrm{~mm}$ between the right and left zygomaticomaxillary sutures. The inter-molar distance and the molar inclination showed increase by $5.3 \mathrm{~mm}$ and $5.4^{\mathrm{O}}$ respectively. Conclusions: MSE is an efficient appliance for producing rapid palatal expansion and mid-palatal suture opening in adult orthodontic patients and can be used as an alternative to the surgically assisted rapid palatal expansion. MSE expansion affects the involved molars, causing increased inter- molar distance with limited buccal tipping.
\end{abstract}

Key words: Rapid maxillary expansion; Maxillary skeletal expander; Mini-implant; CBCT.

\section{INTRODUCTION}

Maxillary transverse deficiency is a problem in orthodontic patients, creating clinical, esthetic, and functional problems that may affect both of the arches. These problems may include crowding, impaction and protrusion of the teeth along with the presence of wide buccal corridors upon smiling $^{(1-3)}$.Transverse maxillary deficiency has been reported to affect $8 \%$ to $23 \%$ of adolescent patients and less than $10 \%$ of adult patients ${ }^{(3-5)}$. The most common finding in maxillary transverse deficiency is unilateral or bilateral cross-bite ${ }^{(1-3)}$.
Maram studied the prevalence of posterior cross bite in Egyptian adolescent population and concluded that, the prevalence of posterior cross bite in Egyptian adolescent population was 7\% with higher incidence in girls than in boys $(6: 4)^{(6)}$.

Maxillary transverse deficiency can be corrected by various appliances and treatment protocols, which usually include maxillary expansion and separation of the mid-palatal suture. This includes rapid palatal expansion (RPE), slow orthodontic expansion (SOE), micro-implant assisted rapid palatal expansion (MARPE), and surgically assisted rapid palatal expansion $(\mathrm{SARPE})^{(7)}$.

\footnotetext{
* Demonstrator, Department of Orthodontics, Faculty of Dental Medicine (Boys, Cairo), Al-Azhar University.

** Associate Professor, Department of Orthodontics, Faculty of Dental Medicine (Boys, Cairo), Al-Azhar University. *** Associate Professor, Department of Orthodontics, Faculty of Dental Medicine (Boys, Cairo), Al-Azhar University.
} 
To determine what type of expansion should be used, the clinician should know the stage of suture fusion in the patient. However, the timing of palatal suture inter-digitation varies among individuals. One study reported that, the transverse growth of the suture continued up to the age of 16 in girls and 18 in boys. ${ }^{(8)}$ Other studies indicated that, the timing of the fusion of mid-palatal suture was noted primarily from 11 to 17 years of age, but occasionally found to occur in older age groups. Meanwhile, some studies showed some patients with no sign of fusion at the age of 32 and $54^{(9-11)}$.

When maxillary expansion is needed, Rapid Palatal Expansion (RPE) which typically uses a tooth-borne appliance with a center jackscrew, is a well-established and reliable technique to correct this problem for adolescent patients ${ }^{(4,12)}$. The suture has been observed to split in a triangle (V) shaped where the base is in the anterior region between the central incisors. This can be clinically observed by the diastema that is created in the anterior region ${ }^{(13,14)}$. For adults, however, nonsurgical RPE with a tooth-borne appliance can result in dento-alveolar tipping that may cause unfavorable periodontal effects due to the interdigitated mid-palatal suture and decreased bone elasticity. Other adverse effects include gingival recession, fenestration of the buccal cortex, buccal tipping of the teeth, alveolar bone bending and palatal tissue necrosis ${ }^{(15-17)}$. Surgically assisted RPE is the conventional treatment of choice to correct transverse maxillary deficiency in adults. However, SARPE is an invasive process that can result in lateral rotation of the 2 maxillary halves with minimal horizontal translation. Also, it may be detrimental to the periodontium and has been shown to result in a large amount of relapse during the post-retention period ${ }^{(15,17,18)}$.

Recently, Micro-implant Assisted Rapid Palatal Expanders (MARPE) have been introduced. It incorporates the micro-implants into the palatal jackscrew that facilitates the palatal expansion without utilizing the dentition as the sole anchorage. MARPE relies on skeletal anchorage obtained through mini-implants to directly apply force to the basal bone ${ }^{(15,16)}$. This concept can eliminate the unwanted results in the conventional palatal expansion. Moreover, bone-borne palatal expanders have recently been reported in several case presentations to have the ability to correct transverse maxillary deficiency in adults, making it a potential alternative to surgically assisted RPE ${ }^{(17,19-21)}$.

For adolescent patients, MARPE has been shown to produce greater transverse skeletal expansion while minimizing dental side effects compared with tooth-borne expansion ${ }^{(22)}$. Due to the increased magnitude of the applied force necessary to split the interlocking suture in adulthood, a new approach to improve mini-implant stability during bone-borne expansion is needed. Bi-cortical mini-implant anchorage has been demonstrated in orthodontics to be bio-mechanically more favorable than mono-cortical anchorage for clinical situations requiring heavy anchorage ${ }^{(23,24)}$.

\section{PATIENTS AND METHODS}

I. Ethical considerations: The objectives of the study were discussed with the patients and / or guardians, and informed consent form and a copy of the instructions of the orthodontic patients were signed before starting the orthodontic treatment.

II. Study design: Prospective clinical study.

III.1. Study setting and population The current study was conducted on 14 adult orthodontic patients (4 males and 10 females). All patients received treatment at the outpatient clinic at Orthodontic Department, Faculty of Dental Medicine, (Boys - Cairo) Al-Azhar University, Egypt. 
III.2. Sample size calculation according to previous studies ${ }^{(25,26)}$ :

Acceptable level of significance $\mathrm{p}<0.05$ (Type I or $\alpha$ error $=5 \%$ ). This means that, the probability that the observed difference "false positive" due to chance is $5 \%$. Power of the study $=0.8$. The "power" of the study then is equal to $(1-\beta)$. This means that, a $20 \%$ failure to detect a difference when actually there is a difference "false negative", i.e. Type II or $\beta$ error $=20 \%$. Expected effect size $=0.29$. The sample size $=12$.

\section{IV.1. Inclusion criteria ${ }^{(12,25-27)}$ :}

- Transverse maxillary deficiency based on the transverse analysis of Andrew's ${ }^{(28)}$ elements.

- $\quad$ Age ranges from 18 to 21 years.

- Treatment strategies employ using skeletal maxillary expansion.

- No cranio-facial syndromes, nor previous orthodontic treatment.

\section{Diagnostic records. (Table: 1)}

TABLE (1) Diagnostic records.

\begin{tabular}{|c|l|l|}
\hline & \multicolumn{1}{|c|}{ Before treatment } & $\begin{array}{l}\text { After } 3 \text { months of the last } \\
\text { activation of the MSE }\end{array}$ \\
\hline $\mathbf{1}$ & $\begin{array}{l}\text { Extra-oral and intra-oral } \\
\text { photographs }\end{array}$ & $\begin{array}{l}\text { Extra-oral and intra-oral } \\
\text { photographs }\end{array}$ \\
\hline $\mathbf{2}$ & $\begin{array}{l}\text { Standardized orthodontic } \\
\text { study models }\end{array}$ & $\begin{array}{l}\text { Standardized orthodontic } \\
\text { study models }\end{array}$ \\
\hline $\mathbf{3}$ & $\begin{array}{l}\text { Cone Beam Computed To- } \\
\text { mography }\end{array}$ & CBCT. \\
\hline
\end{tabular}

The CBCT $^{*}$ images were performed before the start of the expansion (T1) and 3 months after the last activation (T2). All patients did not have brackets nor wires, until after the $\mathrm{T} 2$ records were taken. The CBCT parameters were $90 \mathrm{kVp}, 10 \mathrm{mAs}$, 10.8 seconds scan time and $0.3 \mathrm{~mm}$ voxel size.

\section{Treatment procedures:}

VI.1. Pre-treatment prophylaxis: Dental prophylaxis procedures were performed for each patient, including scaling, polishing and gingival treatment. A written homecare instruction form was given and then all patients in the study were enrolled in a special oral hygiene homecare program for one month to standardize as possible the pre-treatment oral hygiene measures before expansion.

\section{VI.2. Fabrication of the expansion appliance:}

VI.2.1- The MSE: The MSE Version II appliance $^{* *}$ which consists of a central body containing an expansion screw with 4 welded tubes. Each tube is $1.5 \mathrm{~mm}$ in diameter, $2 \mathrm{~mm}$ in length, and acts as insertion slots for placing 4 micro-implants. Each implant is $1.5 \mathrm{~mm}$ in diameter and $11 \mathrm{~mm}$ in length.*** Two molar bands attached to maxillary first molars.

VI.2.2- Appliance positioning: The size of the expander was chosen based on the maximum size that would fit in the palatal vault, while still allowing close adaptation to the tissue surface.

VI.3. MSE delivery: the appliance was tried-in and cemented. Then, the four mini-implants were installed into the expander body, (Figure 1) using manual ratchet wrench for close assessment of torque levels. Lateral cephalometric $\mathrm{x}$-ray was performed to ensure the bicortical engagement of the mini-implants before starting the activation protocol. (Figure 2)

\footnotetext{
* CS 3D imaging version 3.2.12; Care Stream, Italy.

** Biomaterials Korea Inc. Company.

*** OAS-T1511, Biomaterials Korea Inc.
} 


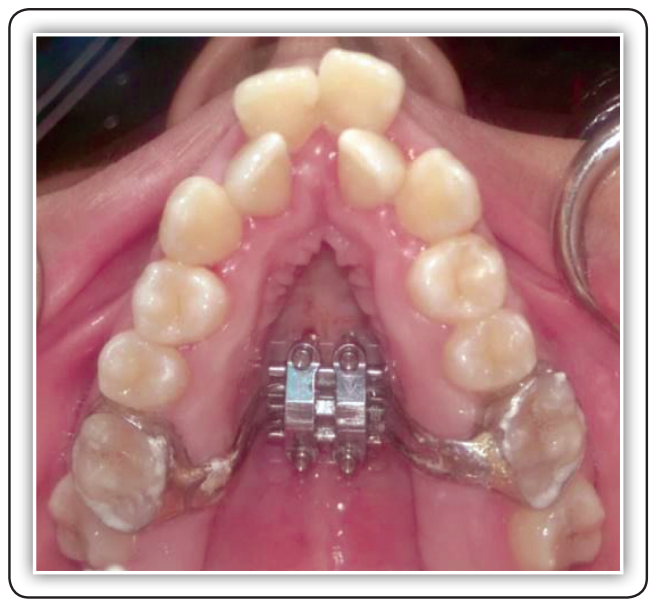

FIG (1) MSE cemented, with mini-implants in-place

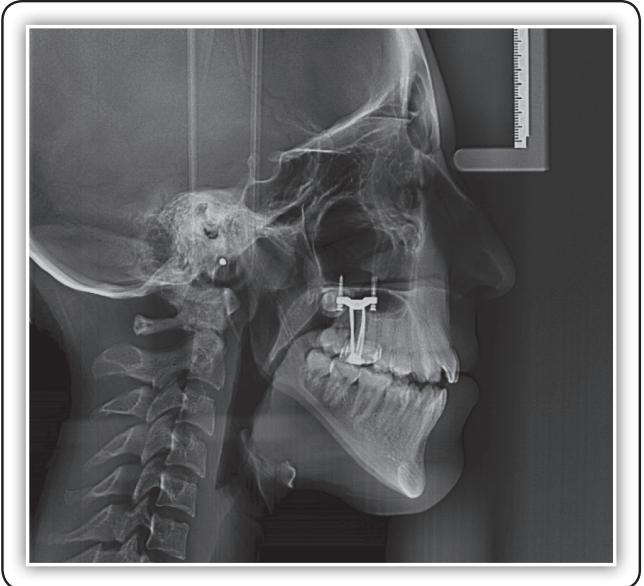

FIG (2) Lateral cephalometric x-ray after mini-implant insertion showing the bi-cortical engagement.

VI.4- Expansion protocol: The initial expansion rate was two turns per day (twice/ daily), till the appearance of the diastema (figure 3). Then, one turn per day. ${ }^{(7)}$ Occlusal radiograph was performed after two weeks from the start of activation to ensure the mid-palatal suture opening. Activation was stopped when the width of the maxillary basal arch became equal to the mandibular one. The appliance was fixed using ligature wire and flowable composite. (Figure 3)

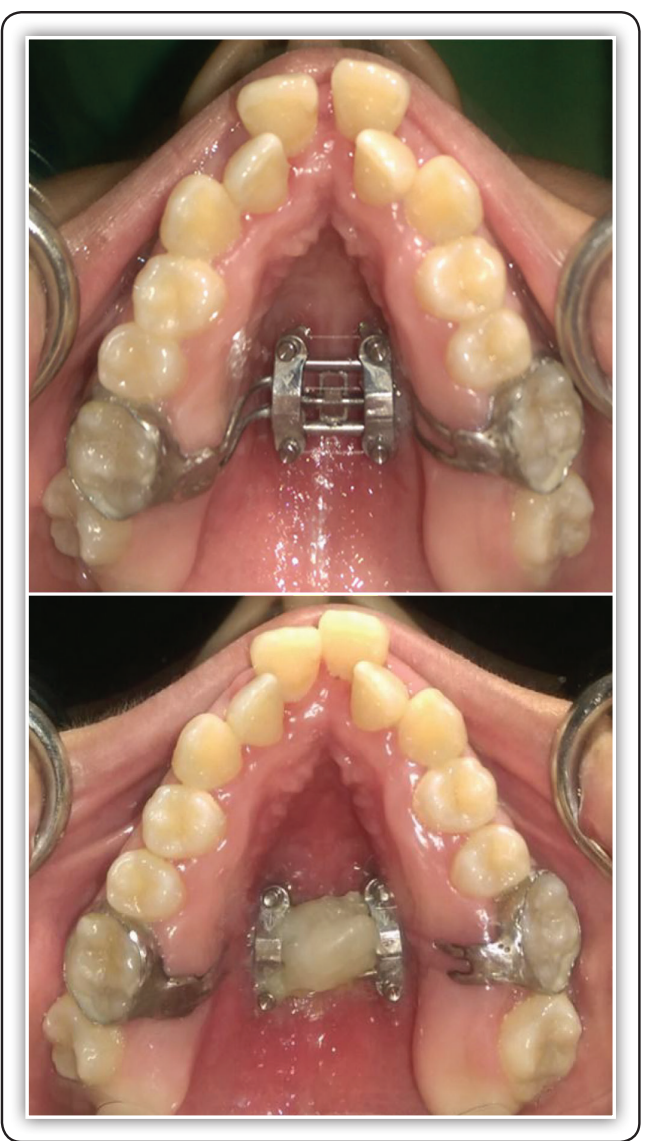

FIG (3) MSE opening and fixation.

\section{Cone beam computerized tomographic (CBCT) analysis: $\left.{ }^{12}, 39-41\right)$}

VII.1: The reference planes. (Figure 4) Three reference planes have been identified ${ }^{(25)}$. in order to orient the skull: The maxillary sagittal plane (MSP), the axial palatal plane (APP), and the vomer coronal plane (VCP). (Table: 2 )

TABLE (2): The reference planes.

\begin{tabular}{|c|l|c|}
\hline $\mathbf{1}$ & Reference plane & \multicolumn{1}{c|}{ Definition } \\
\hline $\mathbf{2}$ & The MSP & $\begin{array}{c}\text { Passes through the anterior nasal } \\
\text { spine (ANS), posterior nasal spine } \\
\text { (PNS) and nasion (N) points on } \\
\text { the pre-expansion CBCT. }\end{array}$ \\
\hline $\mathbf{3}$ & The VCP & $\begin{array}{l}\text { Perpendicular to the MSP and } \\
\text { passes through ANS and PNS. }\end{array}$ \\
\hline & $\begin{array}{c}\text { Perpendicular to the MSP and the } \\
\text { APP and passes through the vomer } \\
\text { (V) point. }\end{array}$ \\
\hline
\end{tabular}




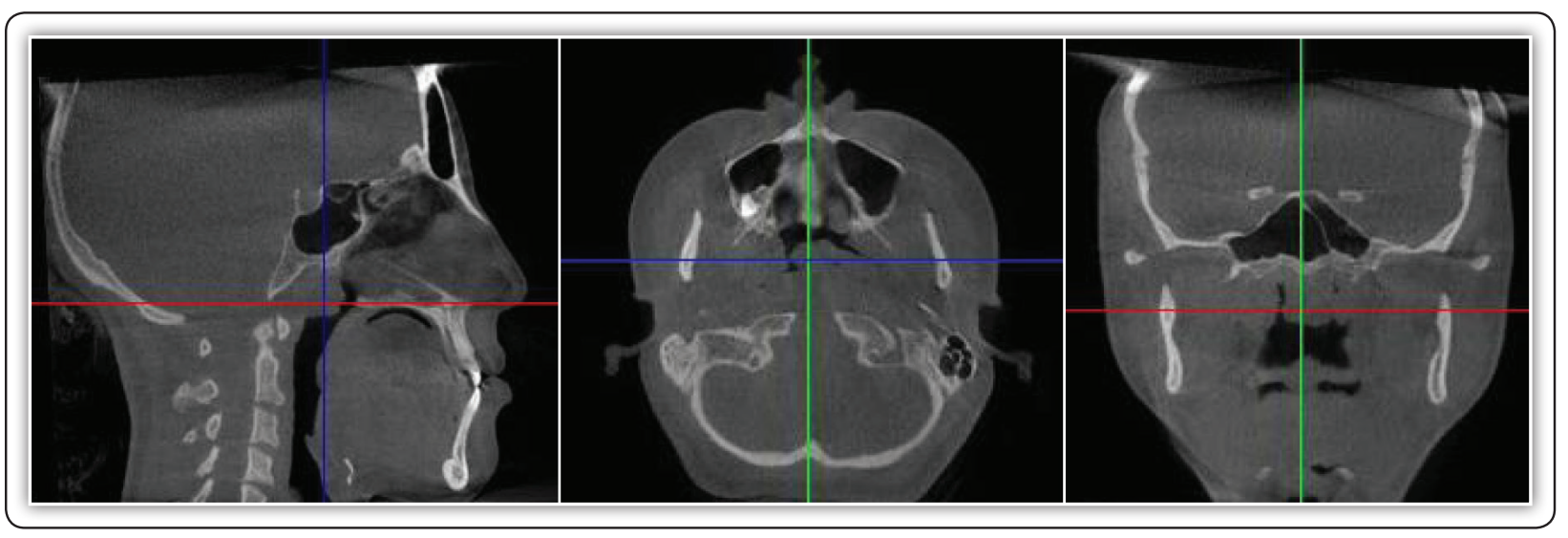

FIG (4) The reference planes.

In order to describe the transverse and the sagittal movement of the maxilla and the pterygoid plates and the modifications in the pterygopalatine suture, three axial sections have been analyzed: The axial palatal section (APS), the axial lower nasal section (LNS), and the axial upper nasal section (UNS). (Table: 3)

TABLE (3): The axial maxillary sections.

\begin{tabular}{|l|l|l|}
\hline & The section & \multicolumn{1}{|c|}{ Definition } \\
\hline A & The APS & Passing through the axial palatal plane. \\
\hline B & The LNS & $\begin{array}{l}\text { Parallel to APP, passes below V point, } \\
2 / 3 \text { the distance between V and APP. }\end{array}$ \\
\hline C & The UNS & $\begin{array}{l}\text { Parallel to the APP and passes through } \\
\text { the V point. }\end{array}$ \\
\hline
\end{tabular}

VII.2: CBCT measurements ${ }^{(25)}$ : The APS was used to study the split of the midpalatal and pterygopalatine sutures. The LNS was used to evaluate the displacement of the maxilla and the pterygoid processes of the sphenoid bone in the transverse and sagittal directions. The UNS was used to evaluate the changes in the maxilla and the pterygoid processes of the sphenoid bone in the transverse and sagittal directions. In order to analyze the skeletal changes of the frontal bone, zygomatic bone and maxilla in the coronal plane, a slice was selected on the CBCT. The coronal zygomatic section (CZS) passes through the upper most point of the right and left frontozygomatic suture, through the lowest point of the right and left zygomaticomaxillary suture, and through Crista galli of the ethmoid bone. In order to analyze the skeletal changes of the temporal bone, zygomatic bone and maxilla in the horizontal plane, the axial zygomatic section (AZS), which passes through the upper part of the right and left glenoid fossae, through the right and left zygomatic process of the temporal bone and through the zygomaticomaxillary suture was used.

Data management and analysis: Data was tabulated and statistically analyzed using Statistical Package for Social Sciences. (IBM ${ }^{*} * \operatorname{SPSS} \AA{ }^{\Theta}$ Statistics Version 20 at $95 \%$ confidence interval).

\section{RESULTS}

Data were represented by mean, standard deviation (SD), with 95\% Confidence Interval (95\% CI) values. Paired t-test, one sample t-test, KolmogrovSamirnov test and descriptive statistics were used to compare between the effect of the treatment on different sections. The significance level was set to $P \leq 0,05$. Two patients were droppedout for different reasons, so, the statistical analysis was performed on 12 patients ( 3 males, 9 females) with their average age $19.3( \pm 1.15)$. (Table: 4$)$

TABLE (4): Descriptive statistics of patient age.

\begin{tabular}{|c|c|c|c|c|}
\hline Number & Mean & SD & Min & Max \\
\hline 12 & 19.3 & 1.15 & 18 & 21 \\
\hline
\end{tabular}

SD: standard deviation. Min: Minimum. Max: Maximum 
The axial palatal section had 4 parameters at the transverse distance, Rt ANS, Lt ANS, Rt PNS and Lt PNS. Each parameter was measured through the distance from the maxillary sagittal plane before and after expansion. As the distance before treatment was zero, all results were significant as $\mathrm{p}=0.0001,0.0005,0.0004$ and 0.0000 respectively of the four parameters. Table (5), figure (5:A).

The axial lower nasal section was measured at the traverse distance from the maxillary sagittal plane and had 6 parameters, Rt Lo Ant Mx, Lt Lo Ant Mx, Rt Lo Post Mx, Lt Lo post Mx, Rt Lo
Pter, Lt Lo Pter which showed significant difference between the pre and post measurements, except the Lt Lo Ant Mx, as p = 0.0493, 0.133, 0.0081, $0.0094,0.043$ and 0.024 respectively. Table (5), figure $(5: \mathrm{B})$.

The coronal zygomatic section had 4 parameters, the lower inter-zygomatic distance, the inter-molar distance and the right and left molar basal bone angles, which showed significant difference between before and after expansion, as p $0.0002,0.0001,0.0000$ and 0.0002 respectively. Table (5).

TABLE (5): Descriptive statistics, one sample t-test and test of significance for the pre and post-expansion in the APS, LNS and CZS.

\begin{tabular}{|c|c|c|c|c|c|}
\hline \multirow[b]{2}{*}{ Axial palatal section } & \multicolumn{2}{|c|}{ Pre } & \multicolumn{2}{|c|}{ Post } & \multirow[b]{2}{*}{$P$ value } \\
\hline & Mean & SD & Mean & SD & \\
\hline Distance of RT ANS from maxillary sagittal plane & 0 & 0 & 1.64 & 1.05 & $0.0001 * * *$ \\
\hline Distance of Lt ANS from MSP & 0 & 0 & 1.32 & 0.99 & $0.0005 * * *$ \\
\hline Distance of Rt PNS from MSP & 0 & 0 & 1.44 & 1.05 & $0.0004 * * *$ \\
\hline Distance of Lt PNS from MSP & 0 & 0 & 1.2 & 0.57 & $0.0000 * * *$ \\
\hline \multicolumn{6}{|l|}{ Axial lower nasal section } \\
\hline Distance of Rt Lo Ant Mx from MSP & 9.64 & 1.43 & 10.51 & 1.14 & $0.0493 *$ \\
\hline Distance of Lt Lo Ant Mx from MSP & 9.52 & 1.35 & 10.32 & 1.21 & $0.133^{\mathrm{NS}}$ \\
\hline Distance of Rt Lo Post Mx from MSP & 21.67 & 1.9 & 22.24 & 2.03 & $0.0081 * *$ \\
\hline Distance of Lt Lo post Mx from MSP & 21.67 & 1.59 & 22.34 & 1.06 & $0.0094 * *$ \\
\hline Distance of Rt Lo Pter from MSP & 17.63 & 1.43 & 18.02 & 1.44 & $0.043^{*}$ \\
\hline Distance of Lt Lo Pter from MSP & 16.92 & 0.76 & 17.37 & 0.84 & $0.024 *$ \\
\hline \multicolumn{6}{|l|}{ Coronal zygomatic section } \\
\hline Inter zygomatic distance & 80.77 & 5.18 & 83.76 & 5.64 & $0.0002 * * *$ \\
\hline Inter molar distance & 39.81 & 5.02 & 45.17 & 5.69 & $0.0001 * * *$ \\
\hline RT molar basal bone angle & 79.19 & 8.6 & 74.46 & 9.6 & $0.0000 * * *$ \\
\hline LT molar basal bone angle & 83.21 & 5.3 & 77.07 & 6.21 & $0.0002 * * *$ \\
\hline
\end{tabular}

SD: Standard deviation $*: P \leq 0.05 . \quad * *: P \leq 0.01 . \quad * * *: P \leq 0.001 . \quad$ NS: Non significant 


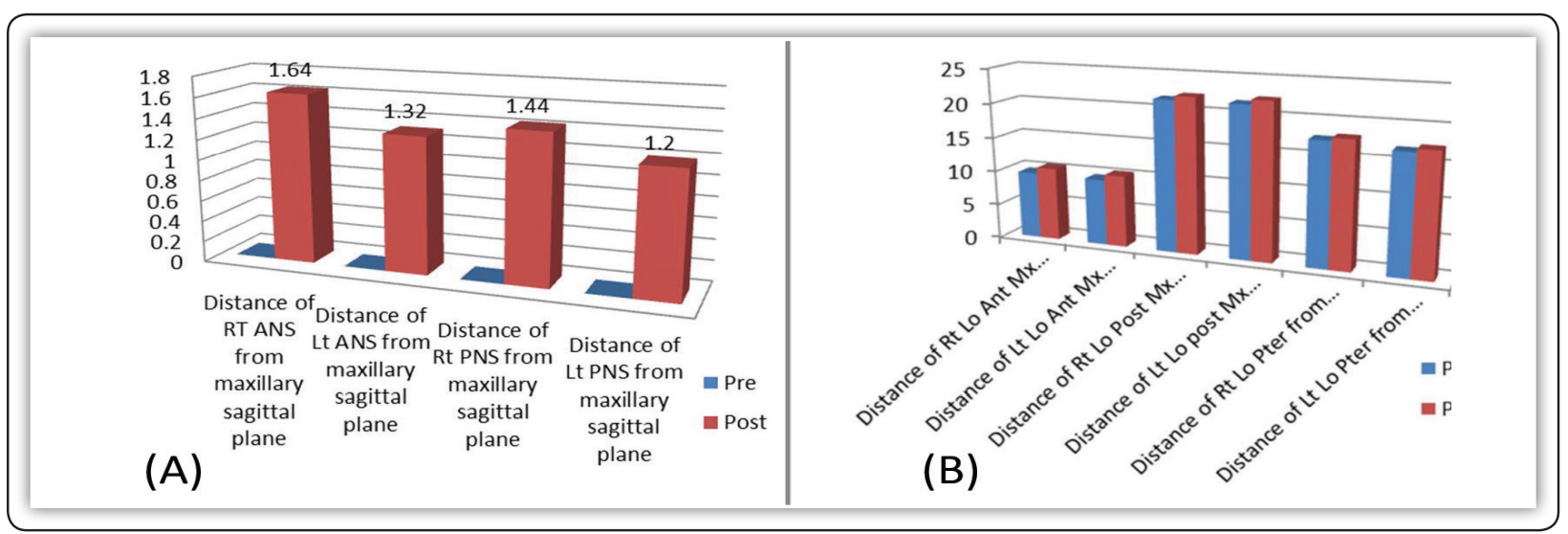

FIG (5) Column chart showing the mean and the standard deviation at the axial palatal section and the axial lower nasal section.

\section{DISCUSSION}

Transvrse maxillary deficiency based on Andrews $^{(28)}$ analysis of six elements, the method adopted consisted in analyzing the relationship between the maxillary and the mandibular width. Maxillary transverse deficiency is calculated as the difference between mandibular and maxillary width, and represents the amount of maxillary skeletal expansion required for the patient as in adult patient, it is very difficult to manipulate the mandibular width without orthognathic surgery ${ }^{(25)}$. Patients were excluded from tooth-borne maxillary expansion and assigned to MSE treatment, based on their maturity, mainly the age (less than 18 years) and cervical vertebral maturation stage less than stage $6^{(29)}$. Pre and post-treatment CBCT images were taken and superimposed. Traditionally, cephalometric superimpositions were most widely used and considered to be the best way to quantitatively assess the skeletal and dental changes associated with orthodontics. Since the evaluation of the measurements in both axial and coronal planes was needed, CBCT images were used in the current study. The appliance was placed as close as possible to the tissue surface between the maxillary first molars. This position was selected to apply lateral forces against the pterygomaxillary buttress bone, which is a major resistance factor in maxillary expansion. The 11- mm length of the mini-implants was chosen by considering the 2-mm height of the insertion slots, the 1 to $2 \mathrm{~mm}$ of space between the appliance and the palatal surface, the 1 to $2 \mathrm{~mm}$ of gingival thickness, and a desired 5 to $6 \mathrm{~mm}$ of bone engagement at a minimum to ensure the bicortical engagement of the mini-implants into the palate and nasal floor ${ }^{(7,25)}$. Moon et al ${ }^{(30)},(2020)$ conducted a study and found that, primary loading of the teeth was envitable when using bone-borne expanders (MSE), without acrylic plate to stabilize the mini-implants during expansion.

The split of the midpalatal suture was analyzed in the axial palatal section and it was found that; the midpalatal suture splits by $2.96 \mathrm{~mm}$ and $2.64 \mathrm{~mm}$ at the ANS and PNS respectively, with a ratio of $89 \%$ between the PNS and the ANS which indicates an almost parallel opening pattern. This agrees with Cantarella et al ${ }^{(25)}$, (2017) who conducted a study using the MSE appliance and produced $4.3 \mathrm{~mm}$. Expansion at the ANS and $4.8 \mathrm{~mm}$. at the PNS with a ratio of $90 \%$ btween PNS and ANS, and disagrees with Haas ${ }^{(31)}$, Wertz ${ }^{(32)}$ and Cozza.et al ${ }^{(33)}$ as they used conventional tooth anchored expanders. The pattern of suture opening was analyzed at the APS, LNS, UNS andAZS and found to be $2.96 \mathrm{~mm}$, $1.67 \mathrm{~mm}, 1.72 \mathrm{~mm}$ and $1.17 \mathrm{~mm}$ for the anterior maxilla and $2.64 \mathrm{~mm}, 1.24 \mathrm{~mm}, 0.96 \mathrm{~mm}$ and $0.7 \mathrm{~mm}$ for the posterior maxilla indicating that, the pattern of expansion was trapezoidal in shape anteriorly 
with the base toward the APP, decreasing gradually toward the AZS but still there is significant amount of expansion anteriorly $(1.17 \mathrm{~mm})$ but on the other hand, the amount of posterior expansion was nonsignificant at the posterior area at the AZS indicating a triangular opening pattern at the posterior maxilla. Till the level of the LNS the opening pattern is still parallel in the axial plane, but becomes less parallel at the level of the UNS and becomes V-shaped at the level of the AZS. This pattern of opening agrees with Cantarella et $\mathrm{al}^{(25)} \operatorname{Lin}^{(26)}$ and Carlson et $\mathrm{al}^{(7)}$, who used bone- anchored expanders, but in disagreement with several studies $(31,32,34)$, who used conventional tooth- borne expanders. The maxillary width showed increase by $2.99 \mathrm{~mm}$ between the right and left zygomaticomaxillary sutures which was statistically significant, this finding was in accordance with previous studies ${ }^{(30,35,36)}$, who reported less, but comparable amounts (2.11-2.6 $\mathrm{mm}$ ) of skeletal expansion when using MARPE. In the present study, the inter molar distance increased by $5.3 \mathrm{~mm}$, this was in accordance to Moon etal $^{(30)}$. The present study showed $5.4^{\mathrm{O}}$ increase in first molar inclination, which was statistically significant and in agreement with Moon et $\mathrm{al}^{(30)}$, and in disagreement with Carlson et $\mathrm{al}^{(7)}$, who recorded a non significant molar tipping when using a MSE in adult patient, but it was a case report.

\section{CONCLUSIONS}

1. MSE is an efficient appliance for producing rapid palatal expansion and mid-palatal suture opening in adult orthodontic patients and can be used as a substitute for SARPE in some cases.

2. The pattern of expansion is almost parallel in the axial palatal section. The opening of the mid-palatal suture at the anterior and posterior nasal spines is comparable.

3. In the coronal section, the mode of expansion is trapezoidal in shape at the anterior maxilla, with the base at the level of APS, decreasing gradually till the AZS, where there is still lesser expansion than the lower sections. The pattern of expansion was $\mathrm{V}$-shaped at the posterior maxilla with the apex superiorly and the base inferiorly.

4. MSE expansion affects the involved molars, causing increased intermolar distance with limited buccal tipping.

\section{REFERENCES}

1. Sarı E, Uçar C, Ceylanoglu C. Transpalatal distraction in a patient with a narrow maxilla. Angle Orthod.2007;77(6):1126-31.

2. Adkins MD, Nanda RS, Currier GF. Arch perimeter changes on rapid palatal expansion. Am J Orthod Dentofacial Orthop.1990;97(3):194-9.

3. Kutin G, Hawes RR. Posterior cross-bites in the deciduous and mixed dentitions. Am J Orthod.1969;56(5):491-504.

4. Brunelle J, Bhat M, Lipton J. Prevalence and distribution of selected occlusal characteristics in the US population. J. Dent. Res. 1996;75(2):706-13.

5. Da Silva Filho OG, Santamaria Jr M, Filho LC. Epidemiology of posterior crossbite in the primary dentition. Int $\mathrm{J}$ Clin Pediatr Dent.2007;32(1):73-8.

6. Maram AM. Prevalence of posterior crossbite i $\mathrm{n}$ Egyptian adolescent population:An epidemiological study. CU Thesis. 2012.

7. Carlson C, Sung J, McComb RW, Machado AW, Moon W. Microimplant-assisted rapid palatal expansion appliance to orthopedically correct transverse maxillary deficiency in an adult. Am J Orthod Dentofacial Orthop.2016;149(5):716-28.

8. Melsen B. Palatal growth studied on human autopsy material: a histologic microradiographic study. Am J Orthod.1975;68(1):42-54.

9. Korbmacher H, Schilling A, Püschel K, Amling M, KahlNieke B. Age-dependent three- dimensional microcomputed tomography analysis of the human midpalatal suture. J. Orofac. Orthop.2007;68(5):364-76.

10. Garrett BJ, Caruso JM, Rungcharassaeng K, Farrage JR, Kim JS, Taylor GD. Skeletal effects to the maxilla after rapid maxillary expansion assessed with cone-beam computed tomography. Am J Orthod Dentofacial Orthop.2008;134(1):8. e1-8. e11. 
11. Kartalian A, Gohl E, Adamian M, Enciso R. Cone-beam computerized tomography evaluation of the maxillary dentoskeletal complex after rapid palatal expansion. Am J Orthod Dentofacial Orthop. 2010;138(4):486-92.

12. Garib DG, Henriques JFC, Janson G, Freitas MR, Coelho RA. Rapid maxillary expansion - tooth tissue-borne versus tooth-borne expanders: a computed tomography evaluation of dentoskeletal effects. Angle Orthod. 2005;75(4):548-57.

13. Timms DJ. A study of basal movement with rapid maxillary expansion. Am J Orthod. 1980;77(5):500-7.

14. Ribeiro GLU, Locks A, Pereira J, Brunetto M. Analysis of rapid maxillary expansion using cone-beam computed tomography. Dental Press J Orthod.2010;15(6):107-12.

15. Ludwig B, Baumgaertel S, Zorkun B, Bonitz L, Glasl B, Wilmes B. Application of a new viscoelastic finite element method model and analysis of miniscrew-supported hybrid hyrax treatment. Am J Orthod Dentofacial Orthop. 2013;143(3):426-35.

16. Crismani AG, Bertl MH, Čelar AG, Bantleon H-P, Burstone CJ. Miniscrews in orthodontic treatment: review and analysis of published clinical trials. Am J Orthod Dentofacial Orthop. 2010;137(1):108-13.

17. Persson M, Thilander B. Palatal suture closure in man from 15 to 35 years of age. Am J Orthod. 1977;72(1): 42-52.

18. Tausche E, Hansen L, Hietschold V, Lagravère MO, Harzer W. Three-dimensional evaluation of surgically assisted implant bone-borne rapid maxillary expansion: a pilot study. Am J Orthod Dentofacial Orthop. 2007;131(4): S92-S9

19. Garib DG, Navarro R, Francischone CE, Oltramari P. Rapid maxillary expansion using palatal implants. J Clin Orthod. 2008;42(11):665-71.

20. Lee K-J, Park Y-C, Park J-Y, Hwang W-S. Miniscrewassisted nonsurgical palatal expansion before orthognathic surgery for a patient with severe mandibular prognathism. Am J Orthod Dentofacial Orthop. 2010;137(6):830-9.

21. Lagravère MO, Carey J, Heo G, Toogood RW, Major PW. Transverse, vertical, and anteroposterior changes from bone-anchored maxillary expansion vs traditional rapid maxillary expansion: a randomized clinical trial. Am J Orthod Dentofacial Orthop. 2010;137(3):304. e1-303. e12.

22. Lin L, Ahn H-W, Kim S-J, Moon S-C, Kim S-H, Nelson G. Tooth-borne vs bone-borne rapid maxillary expanders in late adolescence. Angle Orthod. 2014;85(2):253-62.
23. Holberg C, Winterhalder P, Rudzki-Janson I, Wichelhaus A. Finite element analysis of mono- and bicortical miniimplant stability. Eur J Orthod.2013;36(5):550-6.

24. Brettin BT, Grosland NM, Qian F, Southard KA, Stuntz TD, Morgan TA. Bicortical vs monocortical orthodontic skeletal anchorage. Am J Orthod Dentofacial Orthop. 2008;134(5):625-35.

25. Cantarella D. Skeletal effects induced by Maxillary Skeletal Expander (MSE) and Hyrax appliance in the midface: UCLA Thesis; 2017.

26. Lin L, Ahn H-W, Kim S-J, Moon S-C, Kim S-H, Nelson G. Tooth-borne vs bone-borne rapid maxillary expanders in late adolescence. Angle Orthod. 2014;85(2):253-62.

27. Lin Y. Comparison of skeletal and dental changes with MSE (Maxillary Skeletal Expander) and Hyrax appliance using CBCT imaging: UCLA Thesis; 2015.

28. Andrews L. The six elements of orofacial harmony. Andrews J. 2000;1:13-22.

29. Baccetti T, Franchi L, McNamara Jr JA. The cervical vertebral maturation (CVM) method for the assessment of optimal treatment timing in dentofacial orthopedics. Seminars in Orthodontics; 2005: Elsevier.

30. Moon H-W, Kim M-J, Ahn H-W, Kim S-J, Kim S-H, Chung K-R. Molar inclination and surrounding alveolar bone change relative to the design of bone-borne maxillary expanders: A CBCT study. Angle Orthod. 2020;90(1):13-22.

31. Haas AJ. The treatment of maxillary deficiency by opening the midpalatal suture. Angle Orthod. 1965;35(3):200-17.

32. Wertz RA. Skeletal and dental changes accompanying rapid midpalatal suture opening. Am J Orthod. 1970;58(1):41-66.

33. Lione R, Ballanti F, Franchi L, Baccetti T, Cozza P. Treatment and posttreatment skeletal effects of rapid maxillary expansion studied with low-dose computed tomography in growing subjects. Am J Orthod Dentofacial Orthop. 2008;134(3):389-92.

34. Ghoneima A, Abdel-Fattah E, Hartsfield J, El-Bedwehi A, Kamel A, Kula K. Effects of rapid maxillary expansion on the cranial and circummaxillary sutures. Am J Orthod Dentofacial Orthop. 2011;140(4):510-9.

35. Mosleh MI, Kaddah MA, ElSayed FAA, ElSayed HS. Comparison of transverse changes during maxillary expansion with 4-point bone-borne and tooth-borne maxillary expanders. Am J Orthod Dentofacial Orthop. 2015;148(4):599-607.

36. Choi S-H, Shi K-K, Cha J-Y, Park Y-C, Lee K-J. Nonsurgical miniscrew-assisted rapid maxillary expansion results in acceptable stability in young adults. Angle Orthod. 2016;86(5):713-20. 